\title{
Analysis of Lymphocyte Proliferative Response Subpopulations in Very Low Birth Weight Infants and during the First 8 Weeks of Life
}

\author{
JAMES B. BUSSEL, SUSANNA CUNNINGHAM-RUNDLES, EDMUND F. LAGAMMA, AND \\ MARY SHELLABARGER \\ Department of Pediatrics, Division of Hematology Cornell University Medical Center [J.B.B., S.C.-R., M.S.], and \\ Department of Pediatrics, Division of Neonatology State University for Health Sciences at Stony Brook, New \\ York, New York [E.F.L.]
}

\begin{abstract}
Cell-mediated immunity is not well characterized in very low birth weight infants, and abnormalities may represent a significant vulnerability to infection. This report describes 165 serial studies in 58 infants between 700 and $1300 \mathrm{~g}$ birth weight during the first 8 wk of life. Two $\mathrm{ml}$ of blood were drawn at 2 -wk intervals to measure $T$ cell numbers and subsets and response to phytohemagglutinin (PHA). Overall, lymphocyte proliferation to PHA averaged $17,264 \mathrm{cpm}$, significantly less than the adult control $(23,566 \mathrm{cpm})$. $T$ cell numbers and subsets were CD3 62\% (adult controls 75\%), CD4 45\% (49\%), and CD8 $18.6 \%(27 \%)$. Values at birth were lower as all parameters increased for at least the first 4 wk of life: PHA at birth was $15,464 \mathrm{cpm}, \mathrm{CD3} 48 \%$, CD4 $37 \%$, and CD8 $13 \%$. Because of the lymphocytosis of premature infants, the absolute numbers of total $T$ cells and subsets were within the normal adult range despite less than $50 \%$ of the mononuclear cells at birth being $\mathrm{T}$ cells. A study of five infants demonstrated an average of $52 \% \mathrm{~B} 7+$ cells at birth showing that the number of $B$ cells at birth was increased approximately 10-fold over the control number in adults. Clinical correlation showed that the increases in both the \% CD8 and the absolute number of CD8+ lymphocytes after birth were correlated with both the occurrence of sepsis and the number of red cell transfusions. In summary this study assessed lymphocyte subsets in a sizeable number of very low birth weight infants serially during the first 8 wk of life including lymphocyte function using isolated mononuclear cells. It demonstrated that premature infants are different from adults controls and full term newborns in: 1) having decreased lymphocyte proliferative response to PHA, 2) having lower \% CD3 and CD8, and 3) having an increased number of B cells at birth. (Pediatr Res 23: 457462, 1988)
\end{abstract}

Abbreviations

CMI, cell-mediated immunity

PHA, phytohemagglutinin

VLBWI, very low birth weight infants

RBC Tx, red blood cell transfusion

Received August 11, 1987; accepted December 30, 1987.

Correspondence and reprint requests to James B. Bussel, M.D., Pediatric Hematology/Oncology, New York Hospital-Cornell Medical Center, 525 East 68th Street, New York, NY 10021.
While there have been significant advances in neonatal medicine in the last $10 \mathrm{yr}$, as many as $20 \%$ of infants born in the weight range of 700 to $1300 \mathrm{~g}$ VLBWI do not survive (1). Many of these deaths can be directly or indirectly linked to infection. Despite the fact that abnormalities of CMI could represent a significant vulnerability to infection during early postnatal life, little information exists describing specific potentially important defects in CMI. Therefore, the investigation present herein was undertaken to characterize CMI in VLBWI where the effect on outcome might be most significant.

Previous studies of lymphocyte function and subsets in VLBWI are limited. Only two studies described proliferative responses in a small number of VLBWI $(2,3)$. No serial studies were performed and neither study used isolated mononuclear cells where intrinsic lymphocyte defects could be addressed. Three studies have described $\mathrm{T}$ cell numbers and subsets in VLBWI (4-6). However, B cell numbers were only investigated in one study (not with monoclonal antibodies) (4); studies were repeated in only one report (5) and the third study (6) described the percentage of $T$ cell subsets as a percentage of isolated $T$ cells preventing adequate comparison of their results with those of other studies.

In view of the lack of information characterizing CMI in VLBWI infants and the limited quantity of blood available, we chose to investigate basic parameters in order to begin to define levels of CMI in these premature neonates. Specifically these included lymphocyte function and subset analysis. We were able to use modified techniques $(7,9)$ to permit study of isolated mononuclear cells from a small quantity of blood and therefore to obtain data that could be directly correlated with existing information on term infants, older children, and adults. This report describes 165 serial studies in 58 premature infants of birth weight 700 to $1300 \mathrm{~g}$ including 126 determinations of the response to PHA and 137 determinations of $T$ cell numbers and subsets. B cell numbers were assessed in five VLBWI.

\section{METHODS}

Patient selection. Fifty-eight of 78 babies of 700 to $1300 \mathrm{~g}$ birth weight who were in the New York Hospital Neonatal Intensive Care Nursery during the period of study were enrolled. Babies of mothers known to be at risk of being infected with HIV and babies with severe congenital anomalies would have been excluded from the study but did not occur in these 78 VLBWI. The protocol of study was approved by the Institutional Review Board of the New York Hospital and permission for testing was obtained from the parents of the babies. There were no obvious clinical differences evident between those infants entered in the 
study and those not entered. Specifically there were no significant differences between the 20 infants not entered and the 58 who were enrolled in this study in regard to socioeconomic status, birth weight, rate of sepsis in the first 5 days of life and rate of intracranial hemorrhage as assessed by sonography. Since $70 \%$ of the VLBWI in The New York Hospital Neonatal Intensive Care Unit were born at other hospitals and transported in, some babies who were not enrolled represented the difficulty in obtaining consent under these circumstances. The plan of study involved performing the identical battery of tests (white blood cells with differential, response to PHA, and measurement of T cell numbers and subsets) serially at birth, $2,4,6$, and 8 wk of age; no baby had blood drawn more than five times. Two $\mathrm{ml}$ of heparinized blood at room temperature were obtained at the time of each testing for a total of $10 \mathrm{ml}$ during the entire study distributed over an 8-wk period. VLBWI less than $6 \mathrm{wk}$ old when the study began were enrolled as were VLBWI less than $8 \mathrm{wk}$ of age at the completion of the study. During the first month of study only lymphocyte response to PHA was assayed.

Flow cytometric analysis of T cell numbers and subsets. A total of $0.4 \mathrm{ml}$ of the heparinized blood were removed for lymphocyte subset analysis by flow cytometry of whole blood with fluorescein isothiocyanate conjugated monoclonal antibodies CD3, CD4, and CD8 (obtained from Ortho Diagnostics, Raritan, NJ). A total of $0.1 \mathrm{ml}$ was used per monoclonal antibody tested; the accuracy was verified by dilutional analysis (7). B7 was used in five VLBW to assess expression of $B$ cell surface antigens and to quantitate the number of B cells (8).

Proliferative response to PHA. PHA response was carried out as previously described using a micromethod requiring only 50,000 cells/well (9). In brief, mononuclear cells were isolated by density gradient centrifugation, washed, and resuspended in RPMI 1640 with $25 \mathrm{mM}$ HEPES buffer containing penicillin, streptomycin, $25 \mathrm{M}$ glutamine, and $10 \%$ pooled normal human serum. Mononuclear cells were counted by light microscopy and plated at a density of 50,000 lymphocytes/well in triplicate. Three concentrations of PHA $(75,48$, and $24 \mu \mathrm{g} / \mathrm{ml}$ final concentration) were used to provide a sufficient range to insure that the maximum response was observed. Cultures were pulse labelled with $0.04 \mu 1$ of $\left[{ }^{14} \mathrm{C}\right]$ thymidine on day 3 , harvested by automated Skaatron harvester on day 4 onto glass fiber filters, and counted in a scintillation counter. Data are given as median net maximum response. All studies were conducted in parallel with control blood obtained from hospital personnel as the internal standard.

Clinical correlation. Sepsis was defined as a positive blood culture in the appropriate clinical setting, i.e. hypotension, apnea, bradycardia, etc.

Table 1. $T$ cell numbers and subsets: heparin vs EDTA and same day vs overnight

\begin{tabular}{clccccc}
\hline $\begin{array}{c}\text { Control } \\
\text { patient }\end{array}$ & Anticoagulant & $\begin{array}{c}\text { Day of } \\
\text { assay }\end{array}$ & CD3 & CD4 & CD8 & T4/T8 \\
\hline 1 & EDTA & Same & 65.9 & 36.4 & 27.9 & 1.3 \\
1 & Heparin & Same & 62.7 & 34.7 & 27.9 & 1.2 \\
& & & & & & \\
1 & EDTA & Next & 65.1 & 39.6 & 26.7 & 1.5 \\
1 & Heparin & Next & 63.3 & 37.4 & 28.0 & 1.3 \\
& & & & & & \\
2 & EDTA & Same & 68.6 & 46.5 & 24.3 & 1.9 \\
2 & Heparin & Same & 72.2 & 44.1 & 24.1 & 1.8 \\
2 & & & & & & \\
2 & EDTA & Next & 69.6 & 47.7 & 24.9 & 1.9 \\
3 & Heparin & Next & 70.7 & 47.6 & 24.6 & 1.9 \\
3 & & & & & & \\
& EDTA & Same & 79.9 & 40.9 & 33.4 & 1.2 \\
3 & Heparin & Same & 81.7 & 42.8 & 32.2 & 1.3 \\
3 & EDTA & Next & 82.3 & 48.4 & 32.2 & 1.5 \\
\hline
\end{tabular}

Analysis of data. In the analysis of lymphocyte proliferative response to PHA and of the percentage and number of lymphocyte subsets, these parameters were described by means \pm SD. Differences between groups, i.e. VLBWI versus adult controls, were analyzed using the $t$ test. The Spearman rank order correlation was used to investigate the relationships among different variables, i.e. sepsis and the percent and number of CD8+ cells. Analysis of variance was used to determine the probability that there had been a change in the PHA response, e.g. over the period from 0 to $8 \mathrm{wk}$ postnatal age.

\section{RESULTS}

Experimental approach. Before beginning the study, tests were performed to ensure that the planned studies were feasible with $2 \mathrm{ml}$ of blood and that only one anticoagulant would be required, because in general EDTA anticoagulated blood has been used for cell surface marker analysis. After $0.4 \mathrm{ml}$ of whole blood was removed for surface marker analysis, the mean mononuclear cell recovery from the remaining $1.6 \mathrm{ml}$ in VLBWI was $5.31 \times 10^{6}$, much greater than that seen in adult normals and greatly in excess of the $0.60 \times 10^{6}$ cells required for the lymphocyte activation studies. The least recovery in 126 determinations of PHA was $0.63 \times 10^{6}$ cells. Table 1 demonstrates that there was no difference in the monoclonal antibody analysis when the blood was anticoagulated with heparin versus results obtained with EDTA. In contrast, studies of proliferative response to PHA using blood collected in EDTA revealed a clearly diminished response compared to simultaneous specimens collected in heparin (Table 2); and therefore heparin was used herein. In addition, Table 1 also demonstrates that there was no difference in surface marker expression as a result of routinely holding the specimens overnight before study.

Lymphocyte activation. The mean proliferative response to PHA in 126 determinations in 58 VLBWI was $17,264 \mathrm{cpm} \pm$ 6539 , substantially and significantly $(p<0.01)$ lower than a mean of $23,566 \mathrm{cpm} \pm 5004$ in 112 normal adult controls (Table 3; Fig. 1). Fully $40 \%$ of the determinations in the VLBWI were less than $16,191 \mathrm{cpm}$, which was the least response to PHA of any of the 112 adult normal controls.

Postnatal effects could be excluded as being responsible for the decreased responsiveness to PHA. As illustrated in Figure 1, the

Table 2. Lymphocyte proliferative response to $P H A$ : heparin $v S$ EDTA

\begin{tabular}{clrr}
\hline \multirow{2}{*}{$\begin{array}{c}\text { Cell } \\
\text { donor }\end{array}$} & $\begin{array}{c}\text { Culture } \\
\text { condition }\end{array}$ & \multicolumn{2}{c}{ Anticoagulant } \\
\cline { 2 - 4 } & Heparin & EDTA \\
\hline 1 & Cells alone & 35 & 30 \\
& PHA 3* & 18,732 & 9,866 \\
& PHA 4 & 21,254 & 14,988 \\
& PHA 5 & 18,076 & 14,351 \\
& & & \\
2 & Cells alone & 25 & 45 \\
& PHA 3 & 15,208 & 9,655 \\
& PHA 4 & 22,919 & 14,657 \\
& PHA 5 & 22,763 & 15,765 \\
3 & Cells alone & 130 & \\
& PHA 3 & 12,387 & 35 \\
& PHA 4 & 20,121 & 13,760 \\
& PHA 5 & 21,069 & 14,697 \\
& & & \\
4 & Cells alone & 25 & 30 \\
& PHA 3 & 9,891 & 5,446 \\
& PHA 4 & 14,607 & 9,615 \\
& PHA 5 & 19,820 & 11,941 \\
\hline
\end{tabular}

* Data presented as median net cpm for concentrations of PHA as follows: PHA $3=47 \mu \mathrm{g} / \mathrm{ml}$; PHA $4=25 \mu \mathrm{g} / \mathrm{ml}$; PHA $5=12 \mu \mathrm{g} / \mathrm{ml}$. 


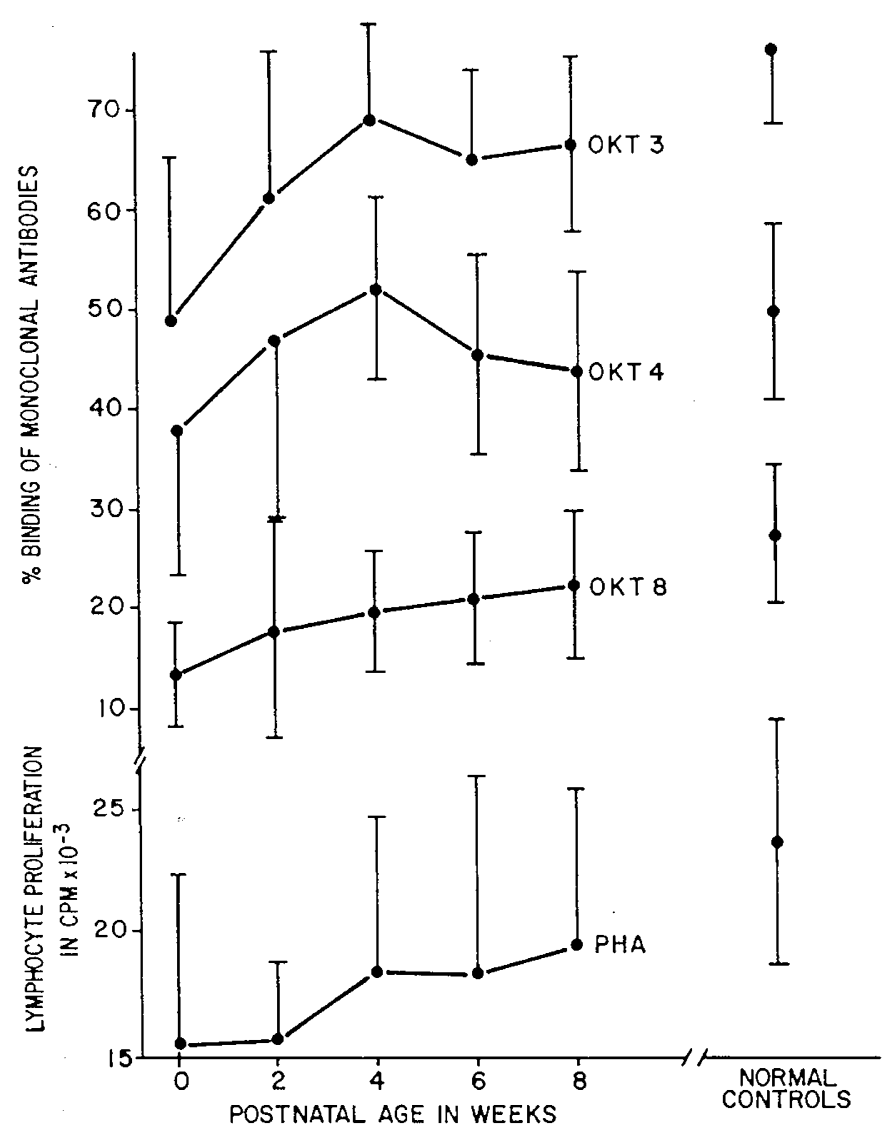

Fig. 1. The Y-axis is the level of CMI either in cpm (bottom, for PHA response) or in percent staining (top, for $\mathrm{CD} 3, \mathrm{CD} 4$, and $\mathrm{CD} 8$ ) expressed as the mean $\pm 1 \mathrm{SD}$. The $\mathrm{X}$-axis is postnatal age in two weekly intervals, the time interval at which the serial immune studies were performed. On the far right is the concurrent adult normal control data. Values for all parameters are low at birth and increase during at least the first $4 \mathrm{wk}$ of life.

Table 3. CMI: all data*

\begin{tabular}{lccccc}
\hline & \multicolumn{5}{c}{ T Lymphocytes } \\
\cline { 2 - 6 } Populations & PHA & CD3 & CD4 & CD8 & CD4/CD8 \\
\hline VLBWI & 17264 & 61.9 & 44.9 & 18.6 & 2.79 \\
& $(126)$ & $(135)$ & $(136)$ & $(137)$ & $(136)$ \\
& 6539 & 14.7 & 13.3 & 8.0 & 1.40 \\
Adult controls & 23566 & 75.0 & 49.0 & 27.0 & 2.00 \\
$(n=112)$ & 5004 & 7.5 & 9.0 & 7.0 & 0.80 \\
\hline
\end{tabular}

* PHA is presented as the mean, the $(n)$, and the $\mathrm{SD}$. The data for $\mathrm{T}$ lymphocytes are similarly presented. The $n$ varied for the VLBWI from assay to assay and therefore is individually listed.

response to PHA tended to increase after birth $(p=0.11)$. In addition, subdividing the wk 0 data to compare specimens obtained on the first day of life to those from days 2, 3, and 4 (from babies born on Friday through Sunday) showed that day 1 proliferative responses tended to be less than those of days 2 to 4 (Table 4).

There was a wide range of proliferative responses to PHA evident both as patient to patient variability as well as intrapatient changes when the same patients were restudied at different time points.

Lymphocyte subpopulation analysis: percentage of cell populations. Lymphocyte surface antigen expression in the VLBWI showed considerably and significantly decreased percentages of CD3 (62 versus $75 \%)$ and CD8 (18.6 versus $27 \%)$ positive cells
Table 4. CMI: initial values

\begin{tabular}{ccllll}
\hline \multicolumn{2}{r}{ PHA } & \multicolumn{1}{c}{ CD3 } & \multicolumn{1}{c}{ CD4 } & \multicolumn{1}{c}{ CD8 } & CD4/CD8 \\
\hline A: Initial values (wk 0) & & & & \\
Mean $\quad 13304$ & 44.9 & 35.8 & 14.0 & 3.07 \\
SD $(n) \quad 4230(27)$ & $18.2(29)$ & $17.7(29)$ & $10.7(29)$ & $1.28(29)$
\end{tabular}

B: Values on day $1 v s$ on days 2,3 , or 4

\begin{tabular}{lcllll} 
Mean & 13396 & 43.9 & 34.7 & 13.4 & 2.90 \\
SD $(n)$ & $6014(17)$ & $16.8(16)$ & $13.2(17)$ & $5.5(17)$ & $1.50(17)$ \\
\multicolumn{5}{c}{ Days 2, 3, or 4 } \\
Mean & 17974 & 56.4 & 41.8 & 13.5 & 3.36 \\
SD $(n)$ & $7363(14)$ & $14.4(9)$ & $14.6(10)$ & $5.6(10)$ & $0.83(10)$ \\
\hline
\end{tabular}

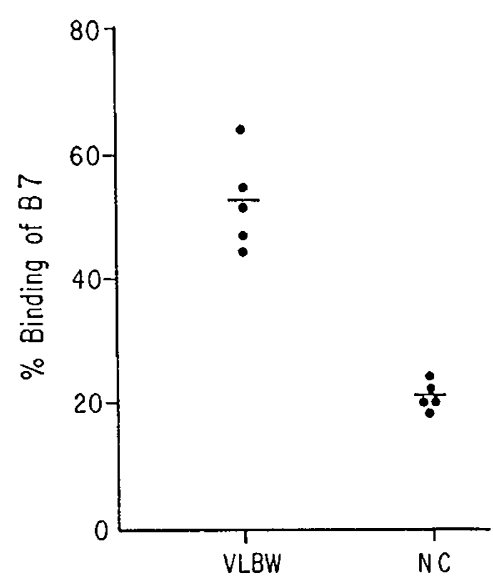

Fig. 2. The $Y$-axis represents the level of percent staining with $B 7$ in five VLBWI and five concurrent adult normal controls with the horizontal lines expressing mean values. The $\mathrm{X}$-axis indicates whether the results are from the VLBWI or normal controls $(N C)$. The mean percent staining with B7 in the VLBWI was $52 \%$ compared to $21 \%$ in the NC indicating, when combined with the lymphocytosis of VLBWI, an at least 10-fold increase in the number of circulating B cells in VLBWI.

compared to normal adult controls; the level of CD4 positive cells (45 versus $49 \%$ ) was not similarly reduced (Table 3 ). The mean \%CD3 at wk 0 was only $48 \%$ : less than half the mononuclear cells at birth in VLBWI were T cells. Studies in five VLBWI demonstrated that the large percent of non-T cells appeared to be mainly B cells (Fig. 2) as evidenced by a mean of $52 \%$ binding with monoclonal antibody $\mathrm{B} 7$ at birth.

As illustrated in Figure 1, the percentages of cells expressing the surface markers defined by CD3, CD4, and CD 8 increased after wk 0 (all $p<0.003$ ). In addition, Table 4 shows that percent staining with all of CD3, CD4, and CD8 were lower for the day 1 specimens than for the day 2 to 4 samples confirming that postnatal events do not explain the decreased percent of $\mathrm{T}$ cells in the VLBWI.

The decreased percentage of $\mathrm{CD} 8$ cells combined with a normal percentage of CD4 cells yielded an increased mean CD4/ CD8 ratio of 2.79 . Only $3 \%$ of the specimens had CD4/CD8 ratios $<1.0$ whereas $34 \%$ of the specimens had a $C D 4 / C D 8$ ratio $>3.0$. Because the CD8+ cells continued to increase after $4 \mathrm{wk}$ postnatal age, the CD4/CD8 ratio remained 3.0 between wk 0 and 4 and then decreased to 2.25 at wk 8 (Fig. 1).

Cell population numbers. The absolute number of lymphocytes at birth was elevated to approximately $5000 / \mu 1$ (Table 5) and this number remained stable for the first $8 \mathrm{wk}$ of life in the VLBWI (see Fig. 3). The absolute number of B cells present at birth was dramatically increased to approximately tenfold that of normal adult levels (Table 4). Whereas the percentage of lymphocytes expressing surface antigens identified by $\mathrm{CD} 3$ and 
Table 5. Absolute numbers of lymphocytes and lymphocyte subsets in VLBWI compared to normal adult controls

\begin{tabular}{lcc}
\hline \multicolumn{1}{c}{ Absolute no. of: } & VLBWI & $\begin{array}{c}\text { Adult } \\
\text { controls* }\end{array}$ \\
\hline Lymphocytes & $4500 \dagger$ & 2314 \\
OKT3+ mononuclear cells & 2000 & 1687 \\
OKT4+ mononuclear cells & 1641 & 1091 \\
OKT8+ mononuclear cells & 620 & 564 \\
B7+ mononuclear cells & 2340 & 210 \\
\hline
\end{tabular}

* Adult control data from Ballow et al. (5).

$\dagger$ Absolute cell counts/ $\mu \mathrm{l}$.

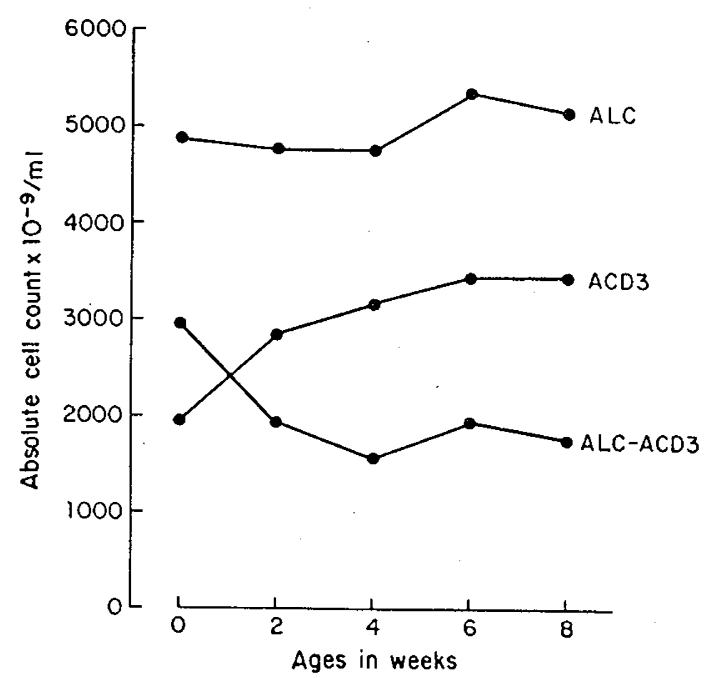

Fig. 3. The $Y$-axis represents the absolute number of cells $\times 10^{-3} / \mu 1$. The $\mathrm{X}$-axis represents time in postnatal age at 2 -wk intervals. $A L C$ is absolute lymphocyte count and was derived from the Coulter counter white blood cell count multiplied by the percentage of lymphocytes. $\mathrm{ACD} 3$ stands for the absolute number of $\mathrm{CD} 3+$ cells derived by multiplying the ALC by the percentage of $\mathrm{CD} 3+$ cells. Inasmuch as the data suggests that ALC-ACD3 would approximately equal the absolute number of B cells (see "Results"), this parameter (ALC-ACD3) was included in the figure to represent the probable changes in the number of $B$ cells in the $8 \mathrm{wk}$ after birth in the VLBWI.

CD8 was significantly decreased at birth, the absolute numbers of $T$ cells and their subsets were not decreased (Table 5; Fig. 4). There was a steady increase in the absolute number of CD8 staining cells during the first 8 wk of life in the VLBWI; CD3+ and CD4+ cells increased during only the first 4 wk of life and then declined slightly.

Proliferative responses to $\mathrm{PHA}$ did not correlate with the percent of mononuclear cells that were CD3, CD4, or CD8 positive or with the CD4/CD8 ratio, or the absolute numbers of lymphocytes, $T$ cells, or $T$ cell subsets and therefore was unlikely to be accounted for as a passive function of cell number or percentage.

Clinical correlation. Clinical correlations of CMI were investigated. Comparing levels of CMI in 26 survivors to five VLBWI who died, no significant differences were seen although the babies who died had lower mean values for all parameters of CMI (PHA, CD3+, CD4+, and CD8+). Birth weight and mode of delivery (vaginal versus cesarean section) were unrelated to parameters of CMI. Only three small for gestational age babies were included in this study; no substantial differences were seen in comparison to appropriate for gestational age babies.

The effects of clinical variables were also assessed by using the changes in the values of CMI between 4,6 , or $8 \mathrm{wk}$ and birth (i.e. \% CD8 at wk 8 minus \% CD8 at wk 0. An increase in both

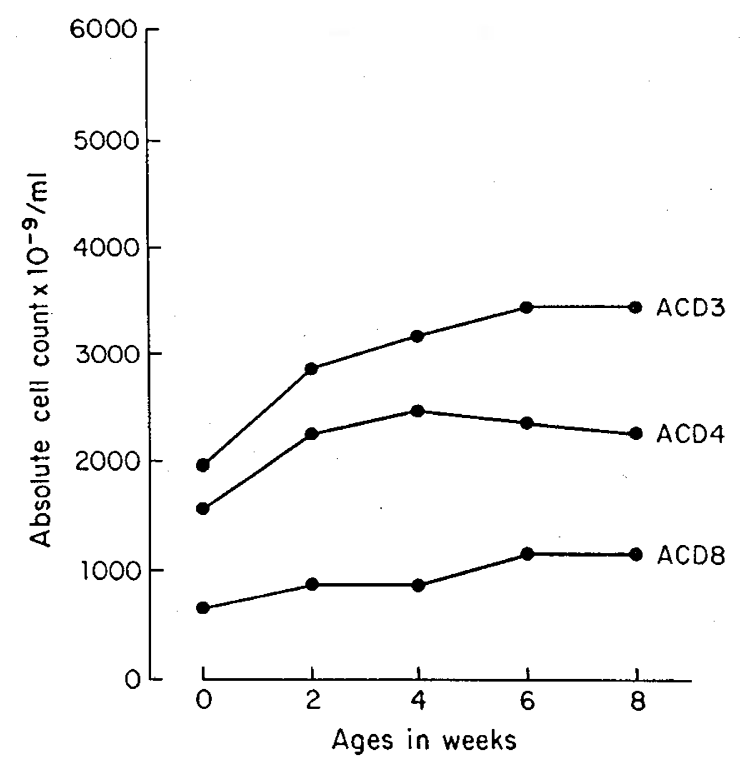

Fig. 4. The $Y$-axis represents the absolute number of cells $\times 10^{-3} / \mu$ l. The $\mathrm{X}$-axis represents time in postnatal age at 2-wk intervals. ACD3, $\mathrm{ACD} 4$, and $\mathrm{ACD} 8$ represents the absolute number of $\mathrm{CD} 3+, \mathrm{CD} 4+$ and CD8+ cells, respectively. These numbers were derived by multiplying the absolute lymphocyte count $(A L C)$ by the percentage of cells staining with the monoclonal antibody (CD3, CD4, or CD8) in question. As seen in figure 1 describing changes in the percent of total $T$ cells and two $T$ cell subsets, there is an increase immediately after birth in all of AT3, AT4, and AT8 but only AT8 was still increasing at 8 wk postnatal age.

the percent CD8 and in the absolute number of CD8+ lymphocytes correlated with both the number of red cell transfusions $(r=0.465$ and $0.466, n=22, p=0.05)$ and with the occurrence of sepsis $(r=0.531$ and $0.482, n=22, p \leq 0.05)$.

\section{DISCUSSION}

This study demonstrates several important differences in parameters of CMI that distinguish VLBWI from both adult controls and (previous reports of) full-term neonates $(10-12)$. These differences are: 1) decreased responsiveness to PHA; 2) lower percentage of cells expressing CD3 and CD8; and 3) higher percentage and number of cells expressing B7. Furthermore the data in Figures 1, 3, and 4 provide a comprehensive description of changes in lymphocyte function and subpopulations to VLBWI during the first $8 \mathrm{wk}$ of life. Whereas the data include sick VLBWI and therefore cannot be used to define "normal" values for VLBWI, nevertheless they allow comparison of individual patients with the values outlined in the Figures 1,3 , and 4. These data suggest that the additional deficits demonstrated in VLBWI as compared to term infants could possibly underlie a component of the morbidity and mortality in VLBWI as has been previously shown in this population for delayed acquisition of humoral immunity (13-15) and for abnormalities of phagocytic cell function (16)

The results of the lymphocyte proliferation in response to PHA in VLBWI reported here and in both previous studies which describe lymphocyte proliferation $(2,3)$ demonstrate decreased lymphocyte responsiveness to stimulation with PHA. It is important to consider that all three studies stand in marked contrast to studies that have established that well full-term newborns have an at least equal to if not greater than normal adult response to PHA (10-12). However, both of the other studies of VLBWI reported a much greater percent decrease in PHA responsiveness than that reported in this study. These differences may be attributed to the use of whole blood in lymphocyte proliferation assays in the previous studies $(2,3)$ and to the use of cord blood $(3)$. 
Study of whole blood, in contrast to isolated mononuclear cells, makes comparisons between individuals difficult because such studies do not correct for the different numbers of lymphocytes in different individuals including the possible adverse effects of "crowding" and, in addition, serum factors may exert an influence on functional activity. Isolated mononuclear cells have not previously been investigated in VLBWI because 10 to $30 \mathrm{ml}$ of blood, a volume that could only be recovered from the umbilical cord at delivery, were required to isolate the requisite number of cells. The lymphocytosis of VLBWI (5) and the ability to use microculture techniques (9) made the use of isolated mononuclear cells in assaying response to PHA possible.

The decreased responsiveness to PHA reported here may reflect an immaturity of the T cells in VLBWI, inasmuch as PHA stimulates primarily $T$ cells (17). The mechanism could lie either in initial activation differences or in reduced secondary recruitment in the amplication phase of proliferation, perhaps related to soluble mediators such as IL-2. Studies in full-term newborns have implicated immaturity of neonatal macrophages in this process $(18,19)$.

A striking finding in this study was the high absolute number and percentage of non-T cells seen in the VLBWI. Whereas the overall percentage of $\mathrm{CD} 3+$ cells was $62 \%$, at birth less than half of the mononuclear cells (48\%) were CD3+. These results contrast with the findings of Ballow et al. (5) who reported $84 \%$ $\mathrm{CD} 3+$ cells at 1 wk of age. The discrepancy between their results and our own may lie in their technique of using buffy coats and washing it rather than direct assays of whole blood. The fact that there were $52 \%$ B7+ cells is consistent with the finding of $48 \%$ $\mathrm{CD} 3+$ cells and indicates that the non-T cells in VLBWI are mainly B cells. The percentage of monocytes in the differential white blood cell count was less than $8 \%$ in the five patients studied with B7 and cytofluorometry studies in an additional five patients using OKM1 also did not find these non-T cells to be monocytes (data not shown) suggesting that the "non- $T$ " cells were indeed B cells. Thomas and Linch (4) also found an increased number of B cells in a small number of VLBWI. Term infants have been reported to have an increased percentage (and absolute number) of B cells, but not to the levels reported here (4). The greatly increased number of B cells in the peripheral blood may have been in transit to different areas of the reticuloendothelial system throughout the body at the time of (premature) birth. Whereas the VLBWI were not serially studied after birth for expression of B7, the significant increase in the absolute number of $\mathrm{CD} 3+$ cells presumably was concomitant with a decrease in circulating B cells as suggested in Figure 3.

The relative importance of the "percentage" that a given cell subpopulation is of the whole in comparison to the "absolute number" of cells of the same subpopulation present in a finite amount of blood is not known at this time. Certainly in VLBWI the $T$ cell abnormalities are considerably more removed from adult normal when considered as percentages than when considered as absolute numbers ( 5 ; this study). The major persistent abnormalities in VLBWI are the large population of non-T cells which have been suggested herein to be B cells and the diminished $T$ cell function evidenced by the reduced response to PHA.

The increased CD4/CD8 ratio found in the VLBWI was the result of a comparatively "normal" percentage of CD4+ cells but a decreased percentage of CD8+ cells; similar results have been previously reported $(4,5)$. Despite the decreased percentage of $\mathrm{CD} 8+$ cells, the absolute number of $\mathrm{CD} 8+$ cells was within the adult normal range. Term newborns have also been shown to have an increased CD4/CD8 ratio at birth although not to the same level as VLBWI $(4,20)$. The correlation between the increase in the percent and absolute number of CD8+ cells after birth with the number of RBC Tx and the occurrence of sepsis suggests that lack of environmental stimulation may contribute to the low percent of CD8+ cells at birth inasmuch as it implies that external stimuli may have long-lived effects on the percent and number of CD8+ cells.
Premature birth may not be solely responsible for the abnormalities in CMI in the weeks after birth, because "postnatal maturation" failed to result in the achievement of term neonate or adult levels of CMI by 8 wk postnatal age. In addition, only PHA and both percent and absolute number of CD8 were still increasing at that time. The one report available to clarify the course of further changes in CMI beyond 8 wk postnatal age in surviving VLBWI has indicated that the CD4/CD8 ratio remained persistently increased throughout the first year of life (5). Presumably the failure of CMI to achieve normal levels by $8 \mathrm{wk}$ of age is also contributed to by postnatal events such as hyaline membrane disease and its associated complications and treatments. The apparent effects of RBC Tx and sepsis have already been alluded to and are consistent with other studies in older patients (20). Surprisingly, the birth weight (within the range $700-1300 \mathrm{~g}$ ) had no observable influence on the levels of CMI. Investigation of other parameters (survival, SGA, mode of delivery) provided less clear results, because of the small sample size. Inasmuch as postnatal events and interventions tend to be both dramatic and cluster together in the sickest VLBWI (e.g. ventilatory support, antibiotics, RBC Tx, vascular access lines, and sepsis), the influence of specific clinical events on CMI may be difficult to delineate without studying very large numbers of VLBWI infants.

In summary it is clear that $\mathrm{T}$ cell numbers, subsets, and function as well as B cell numbers are different from adult controls studied here and from previously reported term newborns. Furthermore these values did not normalize over $8 \mathrm{wk}$ of follow-up. Whether the described abnormalities represent the absence of a maturation process that normally occurs in utero or rather pathologic events set in motion by the prematurity and/ or postnatal events that occur at the premature birth is still not clear. This study implies that all of these factors may act in concert to produce the changes seen. Additional VLBWI need to be studied before the pathophysiology and consequences of the immunologic changes are better understood and any potential role of immunomodulation defined.

\section{REFERENCES}

1. Hack:M, Fanaroff AA, Merkatz IR 1979 The low birth-weight infant: evolution of a changing outlook. N Engl j Med 301:1162-1165

2. Leino A, Ruuskanen O, Kero P, Eskola J, Toivanen P 1981 Depressed phytohemagglutinin and concanavalin A responses in premature infants. Clin Immunol Immunopathol 19:260-267

3. Pittard WB, Miller K, Sorensen RU 1984 Normal lymphocyte responses to mitogens in term and premature neonates following normal and abnormal intrauterine growth. Clin Immunol Immunopathol 30:178-187

4. Thomas RM, Linch DC 1983 Identification of lymphocyte subsets in the newborn using a variety of monoclonal antibodies. Arch Dis Child 58:3438

5. Ballow M, Cates KL, Rowe JC, Goetz C, Pantschenko AG 1987 Peripheral Blood T-cell subpopulations in the very low birth weight (less than $1,500-\mathrm{g}$ ) infant. Am J Hematol 24:85-92

6. Wilson M, Rosen FS, Schlossman SS, Reinherz Ellis L 1985 Ontogeny of human $\mathrm{T}$ and $\mathrm{B}$ lymphocytes during stressed and normal gestation: phenotypic analysis of umbilical cord lymphocytes from term and preterm infants. Clin Immunol Immunopathol 37:1-12

7. Cunningham-Rundles S, Metroka CE, Sofai B, Krim M, Rubin BY, Hayward G 1986 Cytotoxic effector mechanisms in AIDS. In: Gupta S (ed) AIDS Associated Syndromes. Plenum Press, New York, pp 97-110

8. Talle MA, Allegar N, Makowski M, Rao PE, Miller RS, Goldstein C 1983 Classification of human lymphocytes and monocytes with the OK series of monoclonal antibodies. Diagn Immunol 1:129-135

9. Cunningham-Rundles S, Hansen J, Dupont B 1976 Lymphocyte transformation to mitogens and antigens. In: Bach F, Good R (eds) Clinical Immunobiology, vol 3. Academic Press, New York, pp 151-194

10. Griffiths-Chu S, Patterson JAK, Berger CL, Edelson RL, Chu AC 1984 Characterization of immature $T$ cell subpopulations in neonatal blood. Blood 64:296-300

11. Miyawaki T, Seki H, Taga K, Sato H, Taniguchi N 1985 Dissociated production of interleukin- 2 and immune interferon by phytohemagglutin stimulated lymphocytes in healthy infants. Clin Exp Immunol 59:505-511

12. Welte K, Bussel JB, Hilgartner MW, Hertelsmann R 1984 The role of interleukin 2 in the neonate. Pediatr Res 267A

13. Sidiropoulos D, Bohme U, von Muralt G, Morell A, Barandun S 1981 Immunglobulinsubstitution bei der behandlung der neonatalen sepsis. Schweiz Med Wochenschr 111:1649-1655 
14. Ballow M, Cates KL, Rowe JC, Goetz C, Desbonnet C 1986 Development of the immune system in very low birth weight (less than $1500 \mathrm{~g}$ ) premature infants: concentrations of plasma immunoglobulins and patterns of infections. Pediatr Res 20:899-904

15. Chirico G, Rondini G, Piebani A, Chiara A, Massa M, Ugazio AG 1987 Intravenous gammaglobulin therapy for prophylaxis of infection in high-risk neonates. J Pediatr 110:437-442

16. Hill HR 1987 Biochemical, structural, and functional abnormalities of polymorphonuclear leukocytes in the neonate. Pediatr Res 22:375-382

17. Greaves M, Janossy G 1972 Elicitation of selective T and B lymphocyte responses by cell surface binding ligands. Transplant Rev xx:11-87

18. Taylor S, Bryson YJ 1985 Impaired production of gamma interferon by newborn cells in vitro is due to a functionally immature macrophage. $J$ Immunol 134:1494-1497

19. Wilson CB, Hass JF 1984 Cellular defenses against Toxoplasma gondii in newborns. J Clin Invest 73:1606-1626

20. Pahwa S, Sia C, Harper R, Pahwa R 1985 T Lymphocyte subpopulations in high-risk infants: influence of age and blood transfusions. Pediatrics 76:914917

\section{ANNOUNCEMENT}

\section{Call for Abstracts}

A medical and scientific symposium on the etiology, diagnosis, natural history, or treatment of Williams syndrome will be held on August 2, 1988, in Salt Lake City, UT. The deadline for abstracts is June 1, 1988. For additional information please contact: Frank Greenberg, M.D., Texas Children's Hospital, 6621 Fannin, Box 3-210, Houston, TX 77030, (713)791-4774. 